\title{
Characterization of the Phytochemical Constituents of Taif Rose and Its Antioxidant and Anticancer Activities
}

\author{
El-Sayed S. Abdel-Hameed, ${ }^{1,2}$ Salih A. Bazaid, ${ }^{1}$ and Mahmood S. Salman ${ }^{1}$ \\ ${ }^{1}$ Natural Products Analysis Laboratory, Faculty of Science, Taif University, P.O. Box 888, Taif-Alhaweih 21974, Saudi Arabia \\ ${ }^{2}$ Laboratory of Medicinal Chemistry, Theodor Bilharz Research Institute, P.O. Box 30, Imbaba, Giza, Egypt
}

Correspondence should be addressed to El-Sayed S. Abdel-Hameed; shzssayed@yahoo.com

Received 30 April 2013; Accepted 2 September 2013

Academic Editor: Elvira Gonzalez De Mejia

Copyright (C) 2013 El-Sayed S. Abdel-Hameed et al. This is an open access article distributed under the Creative Commons Attribution License, which permits unrestricted use, distribution, and reproduction in any medium, provided the original work is properly cited.

\begin{abstract}
Ward Taifi (Taif rose) is considered one of the most important economic products of Taif, Saudi Arabia. In this study both fresh and dry Taif rose were biologically and phytochemically investigated. The $80 \%$ methanol extracts and $n$-butanol fractions of dry and fresh Taif rose had high radical scavenging activity toward artificial 1,1-diphenyl picrylhydrazyl (DPPH) ${ }^{\circ}$ radical with $\mathrm{SC}_{50}$ values range $5.86-12.24 \mu \mathrm{g} / \mathrm{ml}$ whereas the aqueous fractions showed weak activity. All samples had in vitro anticancer activity toward HepG2 with $\mathrm{IC}_{50}<20 \mu \mathrm{g} / \mathrm{ml}$ which fall within the criteria of the American Cancer Institute. High positive correlation appeared between the antioxidant activity and total phenolics whereas there is no correlation between total phenolics and anticancer activity. The LC-ESI(-ve)-MS analysis of all extracts indicate the presence of phenolic compounds belonging to hydrolysable tannins and flavonol glycosides. In conclusion, the presence of this is considered to be the first phytochemical report that identifies the major compounds in dry and fresh roses using HPLC-ESI-MS. The methanol extracts and its $n$-butanol and aqueous fractions for both fresh and dry Taif rose could be used as preventive and therapeutic effective natural agents for diseases in which free radicals involved after more in vitro and in vivo studies.
\end{abstract}

\section{Introduction}

The use of natural resources especially plants increases daily for the discovery of new therapeutic agents. Medicinal plants are the richest bioresource of drugs in traditional medicines, modern medicines, nutraceuticals, food supplements, folk medicines, pharmaceutical intermediates, and chemical entities for synthetic drugs. Natural products from plants continue to be used in pharmaceutical preparations as crude extracts, fractions, or pure compounds. Several active compounds have been discovered in plants and used directly as patented drugs like Taxol, Artemisinin, and Maprouneacin $[1,2]$. Many studies have proven to be that reactive oxygen species (ROS), and free radicals play a vital role in maintaining human health. When the balance between the generating and scavenging of ROS and free radicals in vivo is destroyed, an oxidative stress would happen, which might lead to extensive oxidative damage to cellular biomolecules, such as DNA, proteins, and lipids. Many chronicdiseases such as hyperlipidemia, hyperpiesia, and cancer have proved to be associated with the existence of oxidative stress [3, 4]. In recent years, several dietary and herbal formulations that have free radical scavenging potential have gained attention in treating such chronic diseases. In spite of the strong radical scavenging activity of synthetic antioxidants, they usually have side effects. Thus the interest in finding natural antioxidants, without undesirable side effects, has increased greatly. The antioxidative phytochemicals especially phenolic compounds found in vegetables, fruits, and medicinal plants have received increasing attention for their potential role in prevention of human diseases [1].

Rosa genus (family Rosaceae) is an important ornamental plant and has been referred to as the queen of flowers. Rosa genus contains over 150 species that are widely distributed in Europe, Asia, Middle East, and North America. Rose is one of the most important crops in the floriculture industry and is used as cut flowers, potted plant, and garden plants. Rose products have also been used in the food, perfumery, and 
cosmetics industries for many years [4-6]. Rosa damascena Mill is one of the most important Rosa species. This plant is called Damask rose because it was originally brought to Europe from Damascus [7]. The main products of Damask rose are rose oil, rose water, rose concrete, rose absolute, and dried petals, and these products are used in perfume, cosmetic, pharmaceutical, and food industries $[5,8,9]$. Flowers of Damask rose were reported to have astringent, analgesic, anti-inflammatory, antidepressant, antibacterial, diuretic, and anti-HIV activity, and they are used in folk medicine as a mild laxative [10-12].

Taif rose, Ward Taifi (Rosa damascena trigintipetala Dieck), is a type of Damask rose which is considered one of the most important economic products of Taif governorate, Saudi Arabia. In this study, the fresh and dry roses were extracted with $80 \%$ methanol followed by partitioning the aqueous solution of extracts with $n$-butanol. The crude $80 \%$ methanol extracts, $n$-butanol, and aqueous fractions were phytochemically and biologically investigated. The biological investigations included in vitro antioxidant and anticancer activity. The total phenolics, flavonoids, and flavonols were estimated, in addition to analysis by hyphenated techniques including high performance liquid chromatography coupled by electrospray ionization mass spectrometry (HPLC-ESIMS).

\section{Materials and Methods}

2.1. Chemicals. All solvents, standards, and reagents are analytical and HPLC grade. 1,1-diphenyl picrylhydrazyl (DPPH) free radical and Folin-Ciocalteu's reagent (FCR) are from Fluka Chemicals. Aluminum chloride, sodium carbonate, sodium phosphate, ammonium molybdate, ascorbic acid, petroleum ether, ethyl acetate, methanol, ethanol, acetic acid, trichloroacetic acid, formic acid, sulphuric acid, sulphorhodamine-B (SRB), catechin, taxifolin, rutin, quercetin 3-O$\beta$-D-glucoside, kaempferol 3-O- $\beta$-D-glucoside, kaempferol 3 -O- $\alpha$-rhamnoside, quercetin $3-\mathrm{O}-\alpha$-rhamnoside, quercetin, and apigenin are from Sigma-Aldrich Chemicals. Solvents for LC-MS (methanol and acetonitrile) are HPLC grade from Sigma-Aldrich Chemicals.

2.2. Collection of Roses and Preparation of Different Extracts and Fractions. During harvest season (March-April 2012), Taif roses were collected from rose farms in the El-Hadda region, Taif governorate, Saudi Arabia. After removing the green parts of roses, part of them was used fresh, and another part was dried on shade air-dried place and powdered using an electric mill. Known weights of cut fresh, and dry powdered rose (900 and $300 \mathrm{~g}$, resp.) were extracted three times by $80 \%$ methanol: $4 \mathrm{~L}$ for fresh rose and $2 \mathrm{~L}$ for dry rose. The solvent was removed under vacuum using rotary evaporator affording known weight of each $80 \%$ methanol extract (112 and $97 \mathrm{~g}$ ). Thirty grams of each $80 \%$ methanol extract were dissolved in $150 \mathrm{~mL}$ distilled water and partitioned with $n$ butanol $(3 \times 150 \mathrm{~mL}$ solvent $)$. The organic and aqueous layers were separated, collected, and evaporated under vacuum using rotary evaporator affording known weight of each respective fraction (9.35 and $10.54 \mathrm{~g}$ for $n$-butanol fraction; 18.65 and $17.27 \mathrm{~g}$ for aqueous fractions). The $80 \%$ methanol extracts, $n$-butanol, and aqueous fractions were stored in brown glass bottles and become ready for investigation.

2.3. Antioxidant Activity. Three different chemical methods were used for evaluating the antioxidant activity of crude methanol extracts, $n$-butanol, and aqueous fractions, 1,1diphenyl picrylhydrazyl scavenging activity, phosphomolybdenum method, and reducing power assay. These assays were performed as described by Abdel-Hameed et al., 2012 [1].

2.3.1. Scavenging Ability towards 1,1-Diphenyl Picrylhydrazyl $(D P P H)^{\bullet}$ Radical. This method depends on the reduction of purple DPPH radicals to a yellow coloured diphenylpicrylhydrazine, and the remaining DPPH radicals which show maximum absorption at $517 \mathrm{~nm}$ were measured using UV-Vis spectrophotometer (Jenway 6405). Two mL of different concentrations of each sample were added to $2 \mathrm{~mL}$ solution of $0.1 \mathrm{mM}$ DPPH. An equal amount of methanol and DPPH served as control. After $20 \mathrm{~min}$ of incubation at $37^{\circ} \mathrm{C}$ in the dark, the absorbance was recorded at $517 \mathrm{~nm}$. The experiment was performed in triplicates. The DPPH radical scavenging activity was calculated according to the following equation:

$\% \mathrm{DPPH}$ radical scavenging activity

$$
=\left[1-\left(\frac{A_{\text {sample }}}{A_{\text {control }}}\right)\right] \times 100,
$$

where $A_{\text {sample }}$ and $A_{\text {control }}$ are absorbance of the sample and control. The $\mathrm{SC}_{50}$ (concentration of sample required to scavenge $50 \%$ of DPPH radicals) values were also determined.

2.3.2. Determination of the Total Antioxidant Capacity by Phosphomolybdenum Method. The assay is based on the reduction of Mo (VI) to Mo (V) by the antioxidants and subsequent formation of a green phosphate/Mo (V) complex at acid pH. $300 \mu \mathrm{L}$ of each sample solution and ascorbic acid $(100 \mu \mathrm{g} / \mathrm{mL})$ were combined with $3 \mathrm{~mL}$ of reagent $(0.6 \mathrm{M}$ sulfuric acid, $28 \mathrm{mM}$ sodium phosphate, and $4 \mathrm{mM}$ ammonium molybdate). A typical blank solution containing $3 \mathrm{~mL}$ of reagent solution and an appropriate volume of the same solvent was used for the sample. All tubes were capped and incubated in a boiling-water bath at $95^{\circ} \mathrm{C}$ for $90 \mathrm{~min}$. After the samples were cooled to room temperature, the absorbance of each sample was measured at $695 \mathrm{~nm}$ against the blank using a UV/Vis spectrophotometer. The experiment was performed in triplicates. The antioxidant activity was expressed as the number of equivalents of ascorbic acid.

2.3.3. Reducing Power Assay. Two $\mathrm{mL}$ of each sample and ascorbic acid in methanol $(200 \mu \mathrm{g} / \mathrm{mL})$ were mixed with $2 \mathrm{~mL}$ of sodium phosphate buffer $(0.2 \mathrm{M}, \mathrm{pH} 6.6)$, and $2 \mathrm{~mL}$ of $1 \%$ $\mathrm{K}_{3} \mathrm{Fe}(\mathrm{CN})_{6}$ were incubated at $50^{\circ} \mathrm{C}$ for $20 \mathrm{~min}$. After adding $2 \mathrm{~mL}$ of trichloroacetic acid, the mixture was centrifuged at $3000 \mathrm{rpm}$ for $10 \mathrm{~min}$. The supernatant solution $(2 \mathrm{~mL})$ was 
taken out and immediately mixed with $2 \mathrm{~mL}$ of methanol and $0.5 \mathrm{~mL}$ of $0.1 \%$ ferric chloride. After incubation for $10 \mathrm{~min}$, the absorbance against the blank was determined at $700 \mathrm{~nm}$ $\mathrm{UV} / \mathrm{Vis}$ spectrophotometer. Triplicates were made for each tested sample and ascorbic acid. The increase in absorbance of the reaction mixture indicates an increased reduction power. The reducing power activity was expressed as the number of equivalents of ascorbic acid.

2.4. Anticancer Activity. The crude methanol extracts, $n$ butanol, and aqueous fractions were investigated in vitro toward human liver carcinoma cell line (HepG2) (obtained frozen in liquid nitrogen $\left(-180^{\circ} \mathrm{C}\right)$ from the American Type Culture Collection and were maintained in the National Cancer Institute, Cairo, Egypt, by serial subculturing), using the method of Skehan et al. (1990) [13] at the National Cancer Institute in Egypt. This is a colorimetric assay that estimates cell number indirectly by staining total cellular protein with the dye sulphorhodamine-B (SRB). This dye is a bright pink aminoxanthrene dye with two sulphonic groups. It is a protein stain that binds to the amino groups of intracellular proteins under mildly acidic conditions to provide a sensitive index of cellular protein content. Cells were seeded in 96-well microtiter plates at a concentration of $5 \times 10^{4}-10^{5}$ cell/well in a fresh medium and left to attach to the plates for $24 \mathrm{~h}$. For each sample, different concentrations $(0,5,12.5,25$, and $50 \mu \mathrm{g} / \mathrm{mL}$ ) were added to wells. Wells were completed to total of $200 \mu \mathrm{L}$ volume/well using fresh medium and incubated for $48 \mathrm{~h}$ at $37^{\circ} \mathrm{C}$ in $5 \% \mathrm{CO}_{2}$. Following $48 \mathrm{~h}$ treatment, the cells were fixed with $50 \mu \mathrm{L}$ cold $50 \%$ trichloroacetic acid for $1 \mathrm{~h}$ at $4^{\circ} \mathrm{C}$. Wells were washed 5 times with distilled water and stained for $30 \mathrm{~min}$ at room temperature with $50 \mu \mathrm{L} 0.4 \%$ SRB dissolved in $1 \%$ acetic acid. The wells were then washed 4 times with $1 \%$ acetic acid. The plates were air-dried, and the dye was solubilized with $100 \mu \mathrm{L} /$ well of $10 \mathrm{mM}$ tris base $(\mathrm{pH}$ 10.5) for $5 \mathrm{~min}$ on a shaker (Orbital Shaker OS 20, Boeco, Germany) at $1600 \mathrm{rpm}$. The optical density (O.D.) of each well was measured spectrophotometrically at $564 \mathrm{~nm}$ with an ELIZA microplate reader (Meter tech. $\Sigma 960$, USA). The mean background absorbances were automatically subtracted, and mean values of each drug concentration were calculated.

The experiment was repeated 3 times. The percentage of cell survival was calculated according to the following equation:

$$
\text { Survival fraction }(\%)=\left[\frac{\text { O.D. of treated cell }}{\text { O.D. of control cells }}\right] \times 100 \text {. }
$$

\subsection{Estimation of the Total Phenolic, Flavonoid, and Flavonol} Contents. In this study, the total phenolic, flavonoid, and flavonol contents of crude methanol extracts, $n$-butanol, and aqueous fractions were measured according to the methods described by Abdel-Hameed, 2009 [14].

The total phenolic content of plant extracts was determined using Folin-Ciocalteu's reagent (FCR). $100 \mu \mathrm{L}$ of each sample solution $(100 \mu \mathrm{g} / \mathrm{mL})$ and also $100 \mu \mathrm{L}$ of gallic acid $(100 \mu \mathrm{g} / \mathrm{mL})$ were mixed with $500 \mu \mathrm{L}$ of the FCR and $1.5 \mathrm{~mL}$ of $20 \%$ sodium carbonate. The mixture was shaken thoroughly and brought up to $10 \mathrm{~mL}$ using distilled water. The mixture was allowed to stand for $2 \mathrm{~h}$. Then the absorbance at $765 \mathrm{~nm}$ was determined against a blank that contained all reagents without the samples or the gallic acid at the same conditions. All determinations were carried out in triplicates. The total phenolic content was expressed as the number of equivalents of gallic acid (GAE).

The flavonoid content was determined by aluminium chloride method using rutin as a reference compound. $100 \mu \mathrm{L}$ of each sample solution $(0.001 \mathrm{~g} / \mathrm{mL})$ was mixed with $100 \mu \mathrm{L}$ of $2 \%$ aluminum trichloride in ethanol and a drop of acetic acid and then diluted with ethanol to $5 \mathrm{~mL}$. The absorption at $415 \mathrm{~nm}$ was read after $40 \mathrm{~min}$. Blanks were prepared from all reagents without the samples. The absorption of the standard quercetin solution $(0.1 \mathrm{mg} / \mathrm{mL})$ in methanol was measured under the same conditions. All determinations were carried out in triplicates. The amount of flavonoids in plant extracts in quercetin equivalents $(\mathrm{QE})$ was calculated by the following formula:

$$
X=\frac{A-m_{o}}{A_{o}-m}
$$

where $X$ is the flavonoid content, $\mathrm{mg} / \mathrm{g}$ plant extract in $\mathrm{QE}, A$ is the absorption of plant extract solution, $A_{o}$ is the absorption of the standard quercetin solution, $m$ is the weight of plant extract $(\mathrm{g})$, and $m_{o}$ is the weight of quercetin in the solution (mg).

The content of flavonols was determined by using quercetin as a reference compound. $1 \mathrm{~mL}$ of each sample solution $(0.001 \mathrm{~g} / \mathrm{mL})$ was mixed with $1 \mathrm{~mL}$ aluminium trichloride $(20 \mathrm{mg} / \mathrm{mL})$ and $3 \mathrm{~mL}$ sodium acetate $(50 \mathrm{mg} / \mathrm{mL})$. The absorbance at $440 \mathrm{~nm}$ was read after $2.5 \mathrm{~h}$. The absorption of the standard quercetin solution $(0.5 \mathrm{mg} / \mathrm{mL})$ in methanol was measured under the same conditions. All determinations were carried out in triplicates. The amount of flavonols in plant extracts in quercetin equivalents (QE) was calculated by the same formula used in flavonoids (3).

\subsection{LC-ESI-MS Analysis}

2.6.1. Preparation of Standard and Sample Solutions. Ten standard stock solutions, catechin $(500 \mu \mathrm{g} / \mathrm{mL})$, taxifolin $(500 \mu \mathrm{g} / \mathrm{mL})$, quercetin-3-O- $\beta$-D-glucoside-6-gallic acid $(500 \mu \mathrm{g} / \mathrm{mL})$, rutin $(500 \mu \mathrm{g} / \mathrm{mL})$, quercetin 3-O- $\beta$-Dglucoside $(500 \mu \mathrm{g} / \mathrm{mL})$, quercetin $3-\mathrm{O}-\alpha-\mathrm{L}-$ rhamnoside $(500 \mu \mathrm{g} / \mathrm{mL})$, kaempferol 3-O- $\beta$-D-glucoside $(500 \mu \mathrm{g} / \mathrm{mL})$, kaempferol 3-O- $\alpha$-L-rhamnoside $(500 \mu \mathrm{g} / \mathrm{mL})$, quercetin $(500 \mu \mathrm{g} / \mathrm{mL})$, and apigenin $(500 \mu \mathrm{g} / \mathrm{mL})$, were prepared in HPLC grade solvent mixture of acetonitrile/methanol/water $(1: 1: 2 ; \mathrm{v} / \mathrm{v} / \mathrm{v})$ and filtered using membrane disc filter $(0.45 \mu \mathrm{m})$. For example, solution $(5 \mathrm{mg} / \mathrm{mL})$ of all samples will prepared in HPLC grade solvent mixture of acetonitrile/methanol/water $(1: 1: 2 ; \mathrm{v} / \mathrm{v} / \mathrm{v})$ and filtered using membrane disc filter $(0.45 \mu \mathrm{m})$.

2.6.2. ESI-MS Direct Infusion. Direct infusion method using ESI-MS (Waters 3100) in negative ion mode was performed to get ESI(-ve)-MS fingerprinting for fresh and dry Taif roses. 
TABLE 1: DPPH free radical scavenging activity, total antioxidant capacity, and reducing power activity of $80 \%$ methanol extracts, $n$-butanol, and aqueous fractions for both fresh and dry Taif rose.

\begin{tabular}{|c|c|c|c|c|}
\hline \multirow[b]{2}{*}{ Extract } & \multicolumn{2}{|c|}{$\mathrm{DPPH}$ free radical scavenging activity } & \multirow{2}{*}{$\begin{array}{l}\text { Total antioxidant capacity } \\
\text { (mg equivalent to ascorbic acid/g } \\
\text { extract) }{ }^{3}\end{array}$} & \multirow{2}{*}{$\begin{array}{l}\text { Reducing power activity } \\
\text { (mg equivalent to ascorbic } \\
\text { acid/g extract) }\end{array}$} \\
\hline & $\mathrm{SC}_{50}(\mu \mathrm{g} / \mathrm{mL})^{1}$ & $\begin{array}{c}(\mathrm{mg} \text { ascorbic acid } \\
\text { equivalent/g extract })^{2}\end{array}$ & & \\
\hline \multicolumn{5}{|l|}{ Fresh roses } \\
\hline $80 \% \mathrm{MeOH}$ & $12.18 \pm 0.07^{\mathrm{c}}$ & $478.59 \pm 2.79^{\mathrm{a}}$ & $357.41 \pm 6.58^{\mathrm{b}}$ & $248.46 \pm 2.70^{\mathrm{b}}$ \\
\hline$n$-Butanol fraction & $5.86 \pm 0.07^{\mathrm{a}}$ & $994.53 \pm 11.90^{\mathrm{c}}$ & $542.45 \pm 9.56^{\mathrm{d}}$ & $432.17 \pm 2.13^{\mathrm{e}}$ \\
\hline Aqueous fraction & $>100^{\mathrm{d}}$ & - & $166.03 \pm 15.36^{\mathrm{a}}$ & $100.54 \pm 2.57^{\mathrm{a}}$ \\
\hline \multicolumn{5}{|l|}{ Dry roses } \\
\hline $80 \% \mathrm{MeOH}$ & $12.24 \pm 0.1^{\mathrm{c}}$ & $476.21 \pm 3.77^{\mathrm{a}}$ & $354.87 \pm 17.96^{\mathrm{b}}$ & $278.80 \pm 13.88^{\mathrm{c}}$ \\
\hline$n$-Butanol fraction & $7.19 \pm 0.08^{\mathrm{b}}$ & $810.96 \pm 9.52^{\mathrm{b}}$ & $504.43 \pm 22.92^{c}$ & $396.72 \pm 6.13^{\mathrm{d}}$ \\
\hline Aqueous fraction & $>100^{\mathrm{d}}$ & - & $157.16 \pm 5.8^{\mathrm{a}}$ & $94.06 \pm 1.77^{\mathrm{a}}$ \\
\hline Ascorbic acid & $5.83 \pm 0.24^{\mathrm{a}}$ & - & - & - \\
\hline
\end{tabular}

Values of $\mathrm{SC}_{50}$, total antioxidant capacity reducing power activity, were expressed as mean of triplicate determinations \pm standard deviation $(n=3)$. Values in the same column followed by a different letter $(\mathrm{a}-\mathrm{e})$ are significantly different $(P<0.05$, ANOVA).

${ }^{1} \mathrm{SC}_{50}$ : concentration in $\mu \mathrm{g} / \mathrm{mL}$ required scavenging the $\mathrm{DPPH}$ radical $(100 \mu \mathrm{g} / \mathrm{mL})$ by $50 \%$. $\mathrm{SC}_{50}$ was calculated by probit-graphic interpolation for six concentration levels.

${ }^{2}$ Radical scavenging activity expressed by mg ascorbic acid equivalent/g extract.

${ }^{3}$ Antioxidant capacity monitored by the phosphomolybdenum method expressed by mg ascorbic acid equivalent/g extract.

${ }^{4}$ Reducing power activity expressed by $\mathrm{mg}$ ascorbic acid equivalent/g extract.

The analytical conditions for injection include the injection of all samples $(5 \mathrm{mg} / \mathrm{mL})$ directly to the ion source by means of a syringe pump at flow rate $(0.02 \mathrm{~mL} / \mathrm{min})$ for ten minutes. The analytical conditions for mass spectrophotometer were capillary voltage $(3 \mathrm{kV})$, cone voltage $(30$ and $70 \mathrm{eV})$, desolvation temperature $\left(350^{\circ} \mathrm{C}\right)$, desolvation gas flow $(700 \mathrm{~L} / \mathrm{h})$, cone gas flow $(50 \mathrm{~L} / \mathrm{h})$, and source temperature $\left(150^{\circ} \mathrm{C}\right)$. Mass spectra were scanned in ESI negative mode in the range between $\mathrm{m} / z$ 50 and 1000. Maslynx 4.1 software was used for data analysis.

2.6.3. LC-ESI-MS Conditions. LC-ESI-MS analysis system consists of HPLC (Waters Alliance 2695) and mass detector (Waters 3100 ). The mobile phases were prepared daily by filtering through $0.45 \mu \mathrm{m}$ membrane disc filter and degassed by sonication before use. The mobile phase for gradient elution consists of two solvents: solvent A $(0.1 \%$ formic acid (FA) in water) and solvent $\mathrm{B}(0.1 \% \mathrm{FA}$ in acetonitrile/methanol $(1: 1 ; \mathrm{v} / \mathrm{v})$. The linear gradient profile was as follows: $95 \% \mathrm{~A}$ (5 min), $95-90 \%$ A (15 min), $90-50 \%$ A (50 min), 50-95\% A (60 min), and 95\% A (65 min). The injection volume was $20 \mu \mathrm{L}$. The flow rate $(0.6 \mathrm{~mL} / \mathrm{min})$ was splitted $1: 1$ before MS interface. The negative ion mode parameters were as follows: capillary voltage $3 \mathrm{kV}$, cone voltage $70 \mathrm{eV}$, source temperature $150^{\circ} \mathrm{C}$, desolvation temperature $350^{\circ} \mathrm{C}$, cone gas flow $50 \mathrm{~L} / \mathrm{h}$, and desolvation gas flow $700 \mathrm{~L} / \mathrm{h}$. Spectra was recorded in the ESI negative mode between $m / z 50$ and 1000. Peaks and spectra were processed using Maslynx 4.1 software. Known peak was identified by comparing its retention time $\left(t_{R}\right)$ and mass spectrum with a known standard. Unknown peak was tentatively identified by comparing its retention time and mass spectrum with literatures.

2.6.4. Calibration Curve and Sample Analysis. Each standard compound was chromatography using the previous analytical conditions. For each standard, the retention time and mass spectrum were determined. From each individual standard stock solution, a mixed stock solution containing ten analytes were prepared and diluted to appropriate different concentrations for establishing calibration curves. For quantitative analysis, six different concentrations of a mixed stock solution containing ten analytes were injected. A calibration curve was obtained by plotting the peak area versus the concentration of each standard. Chromatograms of samples obtained were analyzed using Maslynx 4.1 software based on the comparison of retention times of the samples with those of the standards for qualitative analysis and calibration curve for quantitative analysis.

2.7. Statistical Analysis. All determinations in Tables 1 and 2 were carried out in triplicate and presented as mean \pm SD using SPSS 13.0 program. One-way ANOVA test followed by Duncan's test $(P<0.05)$ was used to analyze the differences among numbers per column. The $\mathrm{SC}_{50}$ values were calculated by probit-graphic interpolation for six concentration levels. The $\mathrm{IC}_{50}$ values in Figure 1 were calculated from survival curve of the tumor cell line by plotting the percent of survival fraction against different concentrations of sample. Correlation analyses were carried out using the correlation and regression by Microsoft Excel program.

\section{Results and Discussion}

The total phenolic contents and biological activity were reported in some Rosa species [12,15-17]. Previous studies of Rosa species relate to the characterization of phenolic compounds by HPLC-UV(DAD) and LC-ESI-MS hyphenated techniques [6, 18-22]. According to our knowledge, until now there are no reports on the LC-MS study of Taif rose either 
TABLE 2: Total amount of phenolic, flavonoid, and flavonol compounds of $80 \%$ methanol extracts, $n$-butanol, and aqueous fractions for both fresh and dry Taif rose.

\begin{tabular}{|c|c|c|c|}
\hline Extract & $\begin{array}{c}\text { Total phenolics } \\
\text { (mg gallic acid equivalent/g } \\
\text { extract })^{1}\end{array}$ & $\begin{array}{c}\text { Total flavonoids } \\
\text { (mg quercetin equivalent/g } \\
\text { extract) }{ }^{2}\end{array}$ & $\begin{array}{c}\text { Total flavonols } \\
\text { (mg quercetin equivalent/g } \\
\text { extract) })^{3}\end{array}$ \\
\hline \multicolumn{4}{|l|}{ Fresh roses } \\
\hline $80 \% \mathrm{MeOH}$ & $61.54 \pm 3.88^{\mathrm{c}}$ & $30.94 \pm 0.39^{c}$ & $21.01 \pm 0.55^{\mathrm{c}}$ \\
\hline$n$-Butanol fraction & $186.84 \pm 6.94^{\mathrm{e}}$ & $63.18 \pm 0.76^{\mathrm{d}}$ & $34.46 \pm 0.58^{\mathrm{d}}$ \\
\hline Aqueous fraction & $7.73 \pm 2.21^{\mathrm{a}}$ & $3.61 \pm 0.34^{\mathrm{a}}$ & $3.08 \pm 0.10^{\mathrm{a}}$ \\
\hline \multicolumn{4}{|l|}{ Dry roses } \\
\hline $80 \% \mathrm{MeOH}$ & $49.38 \pm 1.27^{\mathrm{b}}$ & $24.94 \pm 1.25^{\mathrm{b}}$ & $14.20 \pm 0.59^{\mathrm{b}}$ \\
\hline$n$-Butanol fraction & $177.99 \pm 7.25^{\mathrm{d}}$ & $65.59 \pm 0.82^{\mathrm{e}}$ & $40.51 \pm 0.85^{\mathrm{e}}$ \\
\hline Aqueous fraction & $7.74 \pm 1.91^{\mathrm{a}}$ & $3.74 \pm 0.17^{\mathrm{a}}$ & $2.81 \pm 0.13^{\mathrm{a}}$ \\
\hline
\end{tabular}

Values of $\mathrm{SC}_{50}$, total antioxidant capacity reducing power activity, were expressed as mean of triplicate determinations \pm standard deviation $(n=3)$. Values in the same column followed by a different letter $(\mathrm{a}-\mathrm{e})$ are significantly different $(P<0.05$, ANOVA).

${ }^{1}$ Total phenolics expressed by mg gallic acid equivalent/g extract.

${ }^{2}$ Total flavonoids expressed by mg quercetin equivalent/g extract.

${ }^{3}$ Total flavonols expressed by mg quercetin equivalent/g extract.

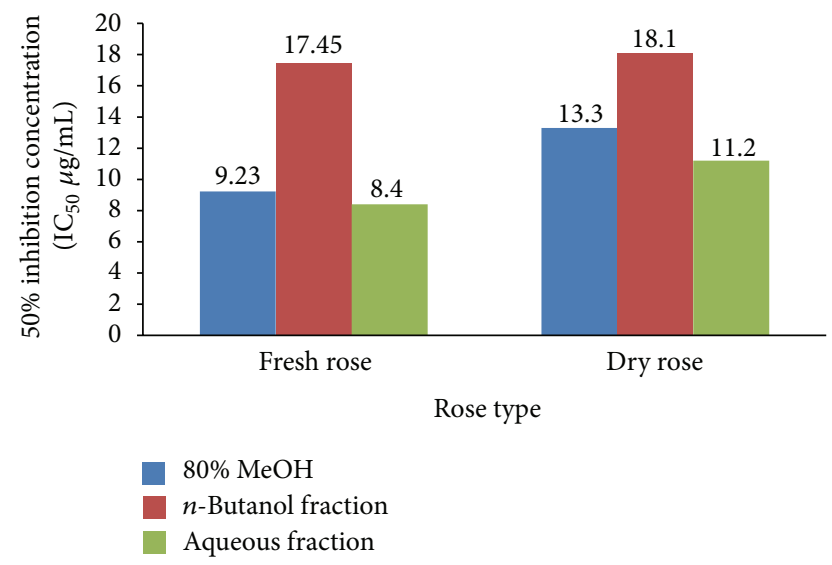

FIgure 1: Cytotoxic activity expressed by $\mathrm{IC}_{50}(\mu \mathrm{g} / \mathrm{mL})$ of $80 \%$ methanol extracts, $n$-butanol, and aqueous fractions for both fresh and dry Taif rose toward human liver carcinoma cell line (HepG2). $\mathrm{IC}_{50}$ calculated from survival curve by plotting the percent of survival fraction against different concentrations of sample.

fresh or dry. In this work, the fresh and dry Taif rose were biologically investigated for their antioxidant and anticancer activity. Phytochemical investigations included estimation of total phenolics, flavonoids, and flavonols with LC-ESI-MS analysis.

3.1. Antioxidant Activity. Free radicals and reactive oxygen species have been proposed to induce cellular damage and to be involved in several human diseases such as cancer, arteriosclerosis, and inflammatory disorders as well as in aging processes [23]. Recently, interest has increased considerably in finding naturally occurring antioxidants for use in foods, cosmetics, or medicinal materials to replace synthetic antioxidants, which are being restricted due to their carcinogenicity [24]. Dietary and herbal formulations which have free radical scavenging potential have gained important in treating such chronic diseases. Many reports attributed the antioxidant properties of vegetables, fruits, and medicinal plants to its contents of phenolic compounds [25-28].

The antioxidant activity of $80 \%$ methanol extracts, $n$ butanol, and aqueous fractions for both fresh and dry rose were chemically estimated by three methods as shown in Table 1. The results obtained from these methods can serve as a significant indicator for the antioxidant activity for samples. Both $80 \%$ methanol extracts for fresh and dry rose exhibited radical scavenging activity on $\mathrm{DPPH}^{*}$ with $\mathrm{SC}_{50}$ values 12.18 and $12.24 \mu \mathrm{g} / \mathrm{mL}$, respectively. The $\mathrm{SC}_{50}$ values nearly equal the half value of standard ascorbic acid. On the other hand, the $n$-butanol fractions for both fresh and dry rose exhibited high radical scavenging activity nearly equal the standard ascorbic acid with $\mathrm{SC}_{50}$ values 5.86 and $7.19 \mu \mathrm{g} / \mathrm{mL}$, respectively, while the aqueous fractions showed very weak activity $>100 \mu \mathrm{g} / \mathrm{mL}$. The determination of total antioxidant activity using phosphomolybdenum method showed that methanol and $n$-butanol fractions for both fresh and dry rose had high antioxidant capacity with values range $354.87-$ $542.45 \mathrm{mg}$ ascorbic acid equivalent/g extract, whereas the aqueous fractions showed weak activity. The methanol and $n$ butanol fractions for both fresh and dry rose exhibited high reducing power activity range $248.46-432.17 \mathrm{mg}$ ascorbic acid equivalent/g extract, whereas the aqueous fractions showed weak activity. It is noticed that the partitioning of crude methanol extracts using organic and aqueous solvents plays important role in separation and concentration of the antioxidant compounds in organic fraction rather than the aqueous fractions. The result of this study was found in agreement with previous studies on the antioxidant activities of some Rosa species [6, 12, 17, 21].

3.2. Anticancer Activity. Cancer is a complicated group of diseases characterized by the uncontrolled growth and spread of abnormal cells, and the mortality that results from the common forms of cancer is still unacceptably high [29]. 
Hepatocellular carcinoma (HCC) is the third most common cause of cancer death in the world [30]. Cancer treatment through chemotherapy has serious limitation including resistance for cancer cells to these chemicals [31]. Thus, it is urgent to find more and more safe new compounds that kill cancer cells. Drug discovery from medicinal plants has played an important role in the treatment of cancer. Most new clinical applications of plant secondary metabolites and their derivatives over the last half century have been applied towards combating cancer [32]. Two plants derived natural products, Paclitaxel and Camptothecin, were estimated to account for nearly one-third of the global anticancer market in total annually in 2002 [33].

Figure 1 shows the cytotoxic effect of crude $80 \%$ methanol extracts, $n$-butanol, and aqueous fractions for both fresh and dry rose $\left(\mathrm{IC}_{50}\right)$ against human hepatocellular carcinoma cell lines (HepG2) using the sulforhodamine B (SRB) method. The SRB method, which was developed by Skehan et al. (1990) [13] remains one of the most widely used methods for in vitro cytotoxicity screening. It has been widely used for drugtoxicity testing against different types of cancerous and noncancerous cell lines [34]. All samples showed high cytotoxic activity toward HepG2 with $\mathrm{IC}_{50}$ ranges $9.23-17.45 \mu \mathrm{g} / \mathrm{mL}$. According to the National Cancer Institute guideline, an extract and/or a compound with $\mathrm{IC}_{50}$ values $<20 \mu \mathrm{g} / \mathrm{mL}$ is considered active [35]. All Taif rose samples showed $\mathrm{IC}_{50}$ fall within this value; thus these samples are considered as promising anticancer agents. It is noticed that the crude $80 \%$ methanol extracts and aqueous fractions for both fresh and dry roses exhibited cytotoxic activity higher than the $n$ butanol fractions, therefore there are more than phytochemical classes responsible for the anticancer activity. In spite of the $n$-butanol fractions showing anticancer activity lower than the other fractions, they still fall within the range of NCI criteria. This result was in accordance with previous reports on the anticancer activity of some Rosa species [36, 37].

3.3. Total Phenolic, Flavonoid, and Flavonol Contents. Many reports attributed the biological properties of roses to its high contents of phenolic compounds $[6,12,16,36-38]$. The total phenolic, flavonoid, and flavonol components of $80 \%$ methanol extracts, $n$-butanol, and aqueous fractions for both fresh and dry rose were estimated (Table 2). The $n$ butanol extracts for both fresh and dry rose has the highest contents (186.84 and $177.99 \mathrm{mg} / \mathrm{g}$ GAE, resp.) followed by methanol extracts (61.54 and $49.38 \pm 1.27 \mathrm{mg} / \mathrm{g}$ GAE, resp.), while the aqueous fractions showed the least amount (7.73 and $7.74 \mathrm{mg} / \mathrm{g}$ GAE, resp.). Table 2 showed that the total flavonoids and flavonols of $n$-butanol fractions for both fresh and dry roses showed the highest content (63.18 and $65.59 \mathrm{mg} / \mathrm{g}$ QE for flavonoids and 34.46 and $40.51 \mathrm{mg} / \mathrm{g} \mathrm{QE}$ for flavonols) followed by $80 \%$ methanol extracts $(30.94$ and $24.94 \mathrm{mg} / \mathrm{g}$ QE for flavonoids and 21.01 and $14.20 \mathrm{mg} / \mathrm{g}$ QE for flavonols), whereas aqueous fractions showed the least amount. It was noticed that there is little difference between the fresh and dried roses in the amounts of total phenolics, flavonoids, and flavonols which may be attributed to the presence of small amount of water in fresh roses that increase the polarity of extraction solvent $(80 \% \mathrm{MeOH})$ during extraction process. Phenolic compounds especially tannins are highly polar compounds and more extracted with highly polar solvent mixtures.

3.4. Correlation between the Total Phenolic, Flavonoid and Flavonol Contents with the Antioxidant and Anticancer Activity. The correlation coefficient between the total antioxidant capacity monitored by phosphomolybdenum method and the total phenolic, flavonoid, and flavonol contents of $80 \%$ methanol extracts, $n$-butanol, and aqueous fractions for both fresh and dry roses was determined. Linear correlation appeared between the total antioxidant capacity and the total phenolic, flavonoid, and flavonol contents with strong correlation coefficient $\left(R^{2}=0.909\right.$ for total phenolics, $R^{2}=$ 0.960 for total flavonoids and $R^{2}=0.928$ for total flavonols). These results are in good accordance with previous studies that showed that high total phenolic content increases the antioxidant activity. The antioxidant activity of the phenolic compounds was attributed to its redox properties, which allow them to act as reducing agents, hydrogen donators, and singlet oxygen quenchers and have also metal chelating properties $[14,39]$. The correlation coefficient between the anticancer activities (mortality percent at $25 \mu \mathrm{g} / \mathrm{mL}$ extract) monitored by SRB method and the total phenolic, flavonoid, and flavonol contents $80 \%$ methanol extracts, $n$-butanol, and aqueous fractions for both fresh and dry roses was determined. No correlation appeared between the anticancer activity and the total phenolic, flavonoid, and flavonol contents. It could be concluded that the phenolic compounds which constitute the major phytochemical class of Taif rose play an important role and are responsible for antioxidant activity, while the cytotoxic activity was found to be associated with the occurrence of other nonphenolic compounds.

3.5. LC-ESI-MS Analysis. Hyphenated HPLC-MS technique is an important method used for identifying complex mixtures, especially the phenolics in the crude extract or its fraction found in the plant, either by using standard compounds (target identification) or by comparing mass spectrum obtained with literatures (tentative identification) $[6,21,40-43]$. This method is useful to avoid replication, safe time, and money used in isolation and identification of known compounds. In this part the different extracts of fresh and dry Taif roses were subjected to HPLC-MS analysis.

After several trials to obtain good separation of the ten standard phenolic compounds mixture by LC-MS (Figure 2), nine sharp peaks were obtained. Good separated eight peaks which correspond to catechin (S1), taxifolin (S2), quercetin-3-O- $\beta$-D-glucoside- $(1 \rightarrow 6)$-gallic acid (S3), rutin (S4), quercetin 3-O- $\beta$-D-glucoside (S5), kaempferol 3-O$\alpha$-L-rhamnoside (S8), quercetin (S9), and apigenin (S10) were obtained. On the other hand, the remaining two standard compounds, quercetin 3-O- $\alpha$-L-rhamnoside (S6) and kaempferol 3-O- $\beta$-D-glucoside (S7), appeared at the same retention time. The MS spectrum of the first half of the peak is characteristic of (S6), whereas the second half is characteristic of (S7). A Calibration curve for each 
TABLE 3: Method validation data for ten phenolic compounds by RP-HPLC-ESI-MS.

\begin{tabular}{lcccc}
\hline Peak number & Compounds & $\begin{array}{c}\text { Sample loading } \\
\text { linearity range }(\mu \mathrm{g})\end{array}$ & Regression equation & $\begin{array}{c}\text { Correlation } \\
\text { coefficient }(r)\end{array}$ \\
\hline S1 & Catechin & $0.1-0.8$ & $y=9 E+06 x+2 E+06$ & 0.878 \\
S2 & Taxifolin & $0.1-0.8$ & $y=2 E+07 x+121352$ & 0.998 \\
S3 & Quercetin-3-glucose- $(1 \rightarrow$ 6)-gallic acid & $0.05-0.4$ & $y=4 E+07 x+181397$ & 0.990 \\
S4 & Rutin & $0.05-0.4$ & $y=3 E+07 x-37568$ & 0.997 \\
S5 & Quercetin 3-O- $\beta$-D-glucoside & $0.05-0.4$ & $y=4 E+07 x+209464$ & 0.995 \\
S6 \& S7 & Quercetin 3-O- $\alpha$-rhamnoside & $0.1-0.8$ & $y=3 E+07 x+1 E+06$ & 0.998 \\
S8 & Kaempferol 3-O- $\beta$-D-glucoside & $0.05-0.4$ & $y=2 E+07 x+123327$ & 0.997 \\
S9 & Kaempferol 3-O- $\alpha$-rhamnoside & $0.025-0.2$ & $y=4 E+07 x-191266$ & 0.998 \\
S10 & Quercetin & $0.025-0.2$ & $y=5 E+07 x+573546$ & 0.996 \\
\hline
\end{tabular}

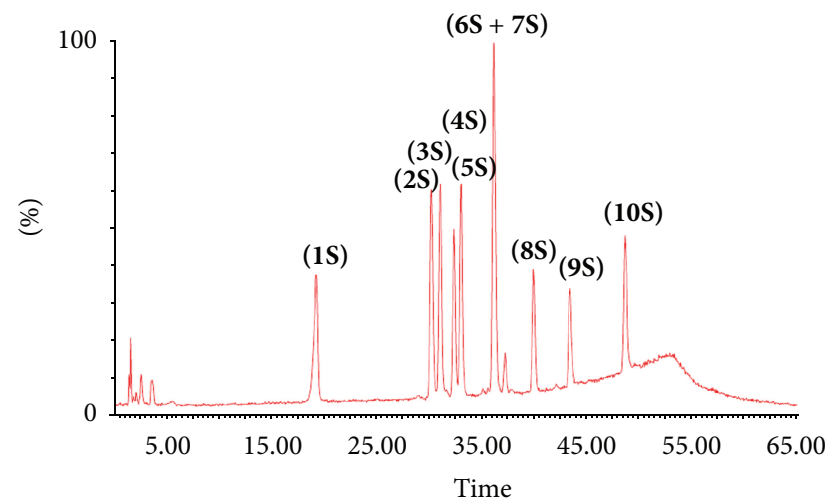

FIgURE 2: Total ion chromatogram of ten phenolic compound standards using LC-ESI negative mass spectrometry: Catechin (S1); taxifolin (S2); quercetin-3-glcucose- $(1 \rightarrow 6)$-gallic acid (S3); rutin (S4); quercetin $3-\mathrm{O}-\beta$-D-glucoside (S5); quercetin $3-\mathrm{O}-\alpha$ rhamnoside (S6); kaempferol 3-O- $\beta$-D-glucoside (S7); kaempferol 3-O- $\alpha$-rhamnoside (S8); quercetin (S9); and Apigenin (S10).

compound in the standard mixture was obtained, and the correlation coefficient revealed a good linearity response for method (Table 3).

The mass spectrum for both methanol and aqueous fractions obtained by direct infusion of samples into the negative ion mode ESI-MS showed the presence of a major peak at $m / z 191$ which was previously detected and identified in other Rosa species as quinic acid [21]. The ESI(-ve)-MS fingerprinting by direct infusion for both methanol and $n$ butanol fractions represents many peaks at $m / z: 169,183,191$, $301,435,447,463,483,593,599,615,635,785$, and 967. The previous peaks may be characterized as gallic acid and its methyl derivatives, quinic acid, flavonoid compounds, and hydrolysable tannins. The aqueous fractions showed peaks at $m / z: 132 ; 179 ; 191 ; 293 ; 341 ; 391 ; 533$. These peaks are characterized by their high polarity and may be attributed to organic acid (e.g., major peak at $m / z 191$; quinic acid), carbohydrate compounds, and unknown highly polar compounds.

After optimizing the LC separation method of standards, the samples were injected in LC-MS under the same conditions. Figures 3 and 4 represent the total ion chromatograms (TIC) of samples obtained from LC-MS. The spectra extracted from each chromatogram were investigated to identify or tentatively identify the components of each sample. The mass analysis of all chromatograms revealed the presence of one organic acid (quinic acid); 2 gallic acid and its mono-methyl derivative; 9 hydrolysable tannins which exhibited strong polarity and shorter retention time under reversed-phase chromatographic conditions; 16 flavonol glycosides of quercetin and kaempferol aglycones; and 1 unknown non phenolic compounds. Figure 5 represents the chemical structures of compounds identified and tentatively identified from fresh and dry Taif rose.

The molecular mass of sugar units in glycosides was calculated from the difference mass of molecular ion peaks, such that a difference of 132 indicates pentose (xylose/arabinose); a difference of 146 indicates deoxyhexose (rhamnose); a difference of 162 mass units indicates a hexose (glucose/galactose); a difference of 176 indicates glucuronic acid. Known peaks were identified by comparing their $t_{R}$ and mass spectra with standards analyzed under the same analytical conditions, whereas unknown peaks were tentatively or postulated identified by comparing their $t_{R}$ and mass spectra with literatures. By comparing, the TIC and mass spectrum of the standard compounds with the methanol, $n$-butanol, and aqueous fractions of fresh and dry Taif rose, five compounds were identified and quantified using calibration curve for each standard (Tables 4 and 5). The identified compounds which are quercetin-3-glucose-(1 $\rightarrow 6)$-gallic acid (12); rutin (14a); quercetin 3-O- $\beta$-D-glucoside (14b); kaempferol 3-O- $\beta$-Dglucoside (19); and kaempferol 3-O- $\alpha$-rhamnoside (23) were found. Traces of compound quercetin 3-O- $\alpha$-rhamnoside are found within the peak 19. The four remaining standard compounds, catechin (S1); taxifolin (S3); quercetin (S9); and apigenin (S10), were not detected. The six identified compounds were previously identified in some Rosa species $[6,21,22]$. Taxifolin was not detected in our work or in previous reports, while catechin, quercetin, and kampferol in addition to luteolin aglycons were detected in some Rosa species but in our work they were not detected $[19,21,44]$. The unknown peaks were tentatively identified based on their $t_{R}$ and mass spectrum comparison with literatures and 


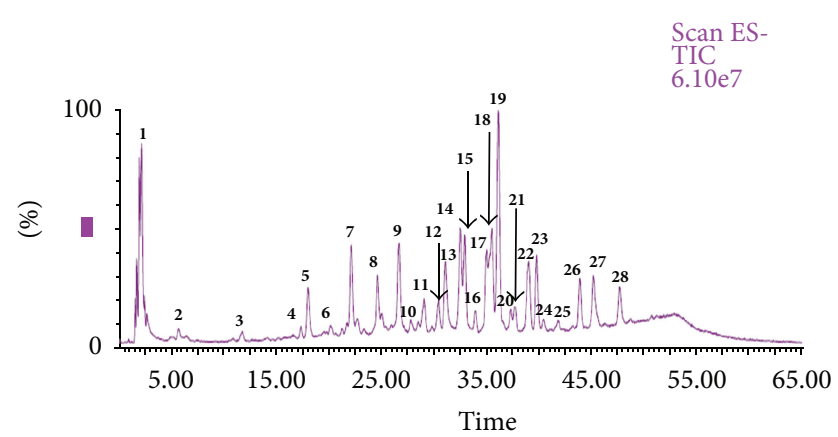

(a)

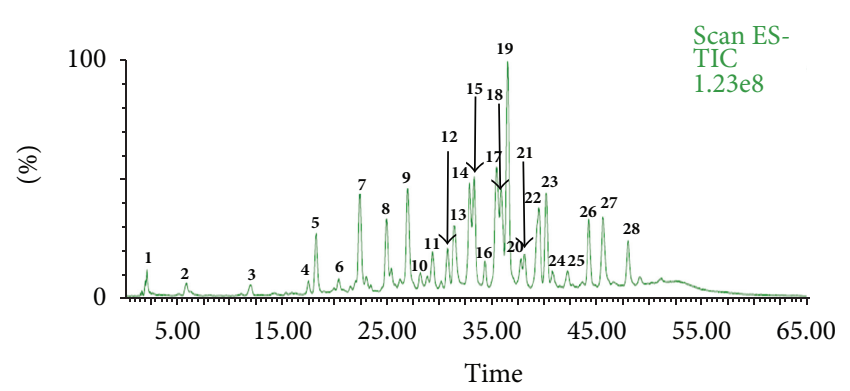

(b)

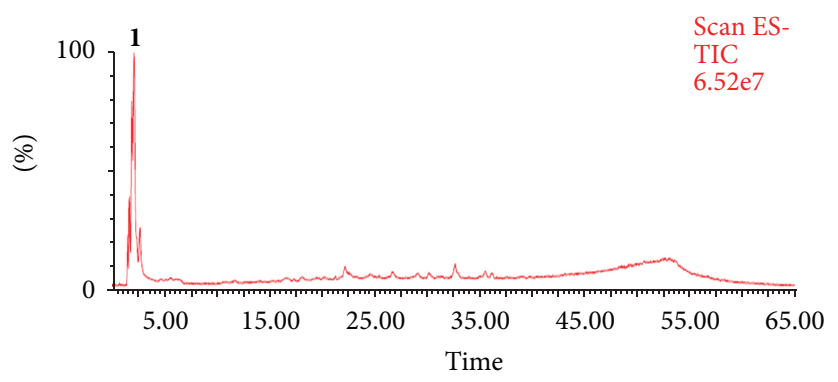

(c)

FIGURE 3: Total ion chromatograms (TIC) of $80 \%$ methanol extract (a), $n$-butanol (b), and aqueous (c) fractions of fresh Taif rose.

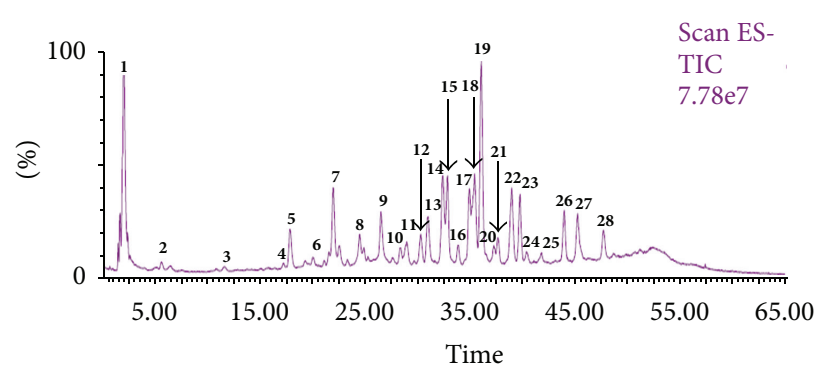

(a)

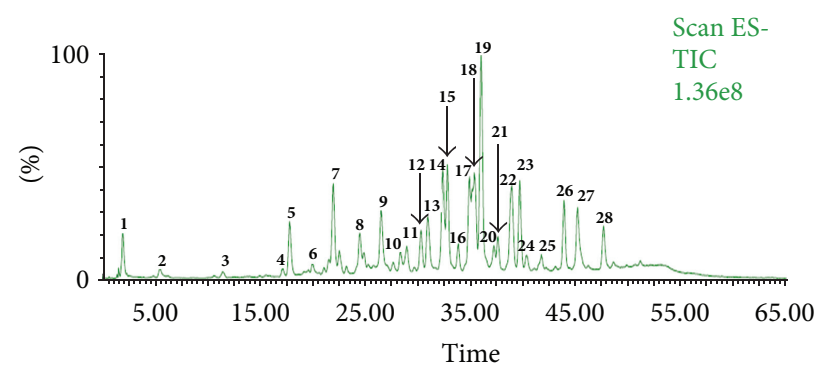

(b)

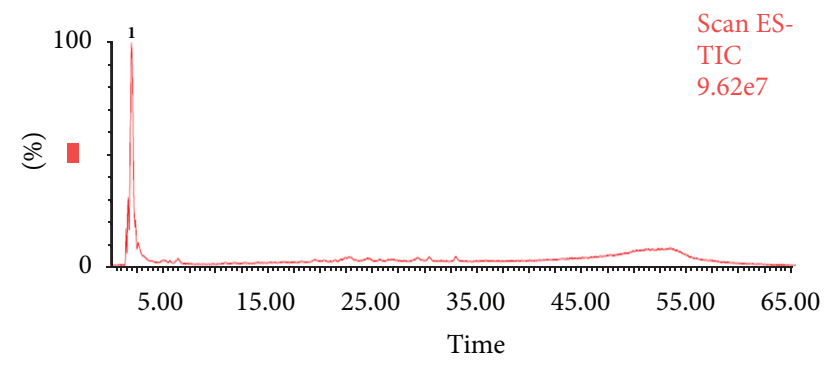

(c)

FIGURE 4: Total ion chromatograms (TIC) of $80 \%$ methanol extract (a), $n$-butanol (b), and aqueous (c) fractions of dry Taif rose.

quantified from the calibration curve of similar standard compounds (Table 5). Compound 1 that showed $\mathrm{m} / z$ at 191 with fragments at $m / z 172,127,93$, and 85 was tentatively identified as quinic acid [41,45]. This compound was also identified in other Rosa species [21]. Compound 2 showed molecular ion peak with $\mathrm{m} / z 169$ which is characteristic of gallic acid by comparison of its mass spectra with literatures
$[42,46]$. This compound was previously identified in some Rosa species including Taif rose $[6,15,21]$. Compound 3 showed mass spectrum with $m / z 483,331,313,169$, and 125 which is characteristic of digalloyl hexose isomer [21, $44,47]$. This compound was also identified in other Rosa species [21,44]. Compound 4 has molecular ion peak at $\mathrm{m} / z 183$ with fragments 169 and 124 , which is characteristic 
<smiles>O=C(O)C1CC(O)C(O)C(O)C1O</smiles>

(1): quinic acid

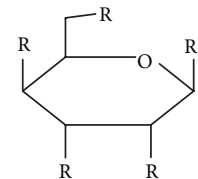

(3): $2 \mathrm{R}=\mathrm{GA}, 3 \mathrm{R}=\mathrm{OH}$

$(5,7): 2 \mathrm{R}=\mathrm{GA}, 2 \mathrm{R}$ (adjacent) $=\mathrm{HHDP}, 1 \mathrm{R}=\mathrm{OH}$ Hexahydroxydiphenic acid (HHDP

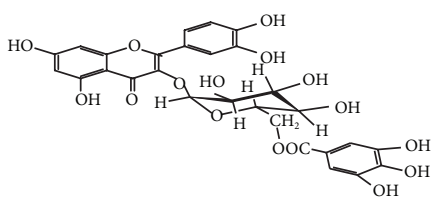

(12): quercetin-3-glucose-6-gallic acid

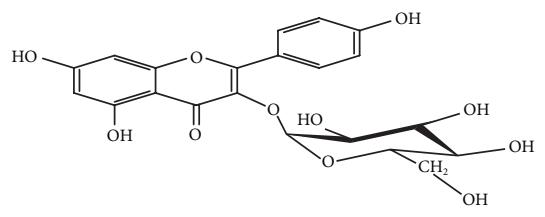

(19): kaempferol 3-O- $\beta$-D-glucoside

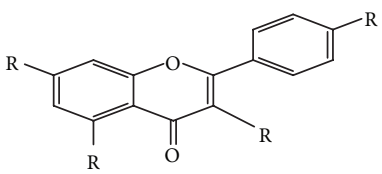

(17): $1 \mathrm{R}=$ hexose, $1 \mathrm{R}=$ gallic acid, $2 \mathrm{R}=\mathrm{OH}$

(20): $1 \mathrm{R}=$ hexose-O-gallic acid, $3 \mathrm{R}=\mathrm{OH}$

(21): $1 \mathrm{R}=$ pentose, $3 \mathrm{R}=\mathrm{OH}$

(22): $1 \mathrm{R}=$ pentose-O-glucuronic acid, $3 \mathrm{R}=\mathrm{OH}$

(26): $1 \mathrm{R}=$ acetyldisaccharides, $3 \mathrm{R}=\mathrm{OH}$

(27): $1 \mathrm{R}=$ hexose, $1 \mathrm{R}=$ deoxyhexose, $2 \mathrm{R}=\mathrm{OH}$

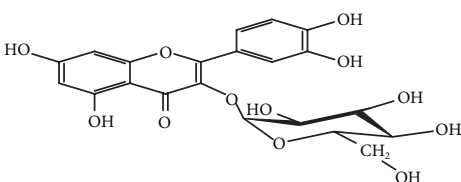

(14b): quercetin 3-O- $\beta$-D-glucoside

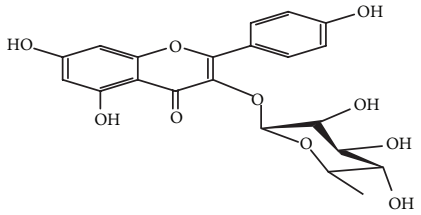

(23): kaempferol 3-O- $\alpha$-rhamnoside<smiles>O=C(O)c1cc(O)c(O)c(O)c1</smiles>

(4): $1 \mathrm{R}=-\mathrm{CH}_{3}, 3 \mathrm{R}=\mathrm{H}$

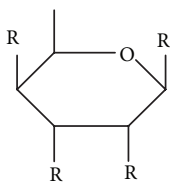

(6): $2 \mathrm{R}=\mathrm{GA}, 2 \mathrm{R}=\mathrm{OH}$

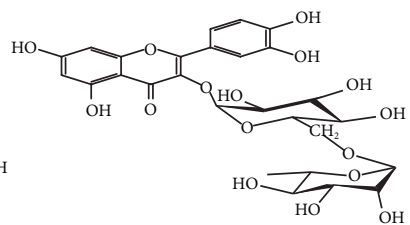

(14a): rutin<smiles>O=C(O)c1ccc(O)c(O)c1</smiles>

Protocatechuic acid<smiles>[R]c1ccc(-c2oc3cc(Br)cc([R])c3c(=O)c2[R])cc1[R]</smiles>

(15): $1 \mathrm{R}=$ hexose- $\mathrm{O}$-protocatechuic acid, $4 \mathrm{R}=\mathrm{OH}$

(16): $1 \mathrm{R}=$ pentose, $4 \mathrm{R}=\mathrm{OH}$

(24): $1 \mathrm{R}=$ acetyldisaccharides, $4 \mathrm{R}=\mathrm{OH}$

(25): $1 \mathrm{R}=$ hexose, $1 \mathrm{R}=$ deoxyhexose, $3 \mathrm{R}=\mathrm{OH}$

Figure 5: Chemical structures of compounds identified and tentatively identified from fresh and dry Taif rose.

to mono-methyl gallic acid derivative [48-50]. Peaks 5 and 7 showed the same molecular ion peak at $\mathrm{m} / z 785$ and similar fragments. These two compounds were tentatively identified as HHDP-digalloyl hexose isomers [40, 42, 44, 51]. On the other hand, peak 6 showed a molecular ion peak at $m / z 465$ with fragments $313,301,169$, and 125 which could be postulated to be digalloyl deoxyhexose isomer. The mass spectral data of peaks 8-11 and 13 were found in accordance with and associated to different isomers of unknown ellagitannins [40, 44, 47, 49, 51, 52]. Peak 15 showed molecular ion peak at $m / z 599$ with fragments 463,300 , 179,169 , and 151. The difference between ion at $m / z 599$ of 463 , and 300 revealed the loss of two consecutive ions with 162 and 136 mass units which is characteristic to hexose sugar (galactose/glucose) and protocatechuic acid. Then this compound could be tentatively identified as quercetinhexose-protocatechuic acid isomer, and it could be a good candidate for target separation and isolation. Peak $\mathbf{1 6}$ showed molecular ion peak at $m / z 433$ with fragments 301,179 and 151 that is characteristic of quercetin-O-pentoside isomer $[43,44$, 50]. Peaks 17 and 20 showed the same ion molecular peak at $\mathrm{m} / z 609$ with fragments $447,435,284,169$, and 151 for peak 17 and fragments $447,284,197,169$, and 151 for peak 20 . The two compounds could be tentatively identified as kaempferol-Ohexose-O-gallic acid isomers in which compound $\mathbf{1 7}$ contains hexose and gallic acid in different situation. While compound 20 contains combined hexose-gallic acid [22], the mass spectrum of peak 18 showed that the presence of a mixture of two compounds is characteristic of kaempferol and quercetin disaccharides derivatives [22, 43, 50]. Peak 21 has 
TABLE 4: Peak assignment, molecular weight (MW), molecular ion $\left(\mathrm{M}^{-}\right)$, mass ion fragments, and tentative identification of compounds detected in $80 \%$ methanol extract, $n$-butanol, and aqueous fractions of fresh and dry Taif rose by LC-ESI(-ve)-MS.

\begin{tabular}{|c|c|c|c|c|}
\hline \multirow{2}{*}{ Peak number } & \multirow{2}{*}{ MW } & \multicolumn{2}{|r|}{$m / z$} & \multirow{2}{*}{ Tentative identification } \\
\hline & & $\mathrm{M}^{-}$ & Fragments & \\
\hline 1 & 192 & 191 & $127,93,85$ & Quinic acid \\
\hline 2 & 170 & 169 & 125,79 & Gallic acid \\
\hline 3 & 484 & 483 & $331,313,169,125$ & Digalloyl hexose \\
\hline 4 & 184 & 183 & $169,147,124,78$ & Methyl gallic acid derivative \\
\hline 5 & 786 & 785 & $633,615,483,301,169,125$ & Digalloyl DHHP hexose \\
\hline 6 & 466 & 465 & $313,301,169,147,125$ & Digalloyl deoxyhexose \\
\hline 7 & 786 & 785 & $633,615,483,331,313,301,169,125$ & Digalloyl DHHP hexose \\
\hline 8 & 968 & 967 & $785,765,667,505,301,183,169$ & Unknown ellagitannin \\
\hline 9 & 968 & 967 & $785,765,633,615,483,451,301,182,169,125$ & Unknown ellagitannin \\
\hline 10 & 938 & 937 & $783,657,465,301,169,125$ & Unknown ellagitannin \\
\hline 11 & 968 & 967 & $785,765,639,450,314,301,169,147,124$ & Unknown ellagitannin \\
\hline 12 & 616 & 615 & $463,313,301,169$ & Quercetin-3-glucose- $(1 \rightarrow 6)$-gallic acid \\
\hline 13 & 938 & 937 & $785,766,615,313,301,183,169,125$ & Unknown ellagitannin \\
\hline $14 a$ & 610 & 609 & 463,301 & Rutin $^{\mathrm{a}}$ \\
\hline $14 b$ & 464 & 463 & $301,229,179,150$ & Quercetin 3-O- $\beta$-D-glucoside $^{\mathrm{a}}$ \\
\hline 15 & 600 & 599 & $463,300,179,169,151$ & Quercetin-hexose-protocatechuic acid \\
\hline 16 & 434 & 433 & $301,151,179$ & Quercetin-O-pentose \\
\hline 17 & 600 & 609 & $447,435,284,169,151$ & Kaempferol-hexose-gallic acid \\
\hline 18 & $610 / 594$ & $609 / 593$ & $435,433,301,285,169,151$ & Quercetin/Kaempferol derivatives \\
\hline 19 & 448 & 447 & $284,179,151$ & Kaempferol 3-O- $\beta$-D-glucoside ${ }^{a}$ \\
\hline 20 & 600 & 599 & $447,285,197,169,151$ & Kaempferol-O-hexose-O-gallic acid \\
\hline 21 & 418 & 417 & $284,197,227$ & Kaempferol-O-pentose \\
\hline 22 & 594 & 593 & $417,285,197,151,147$ & Kaempferol-O-pentose-O-glucuronic acid \\
\hline 23 & 432 & 431 & $284,255,227$ & Kaempferol 3-O- $\alpha$-rhamnoside ${ }^{a}$ \\
\hline 24 & 652 & 651 & $609,447,301,147$ & Quercetin acetyldisaccharides \\
\hline 25 & 610 & 609 & $463,447,301,147$ & Quercetin-O-hexose-O-deoxyhexose \\
\hline 26 & 636 & 635 & 487,285 & Kaempferol acetyldisaccharides \\
\hline 27 & 594 & 593 & $447,430,285,151$ & Kaempferol-O-hexose-O-deoxyhexose \\
\hline 28 & 605 & 604 & $582,462,342$ & Unknown non-phenolic compound \\
\hline & & & Standard compounds & \\
\hline S1 & 290 & 289 & $244,221,150,136,123$ & Catechin \\
\hline S2 & 304 & 303 & $284,274,217,179,151$ & Taxifolin \\
\hline S3 & 616 & 615 & $463,313,301,271,169,151,147$ & Quercetin-3-glucose-6-gallic acid \\
\hline S4 & 610 & 609 & $463,301,179,151,147$ & Rutin \\
\hline S5 & 464 & 463 & $300,271,254,179,151$ & Quercetin 3-O- $\beta$-D-glucoside \\
\hline S6 & 448 & 447 & $300,270,179,151$ & Quercetin 3-O- $\alpha$-rhamnoside \\
\hline S7 & 448 & 447 & $284,179,151$ & Kaempferol 3-O- $\beta$-D-glucoside \\
\hline S8 & 432 & 431 & $248,254,227,198,147$ & Kaempferol 3-O- $\alpha$-rhamnoside \\
\hline S9 & 302 & 301 & 179,151 & Quercetin \\
\hline S10 & 270 & 269 & $225,199,159,151,117$ & Apigenin \\
\hline
\end{tabular}

${ }^{\mathrm{a}}$ Compounds identified by comparison with standards.

a molecular ion peak at 417 with fragment at 284 in its mass spectrum. The difference between the molecular ion and its fragments (133 mass units) revealed the occurrence of pentose sugar (xylose/arabinose) attached to aglycon. Compound 21 could be tentatively identified as kaempferol-pentoside isomer [21, 22, 53]. Peak 22 with a molecular ion peak at $\mathrm{m} / z 593$ with fragments 417 and 285 could give indication of the presence of pentose and glucuronic acid sugar moieties. This compound could be tentative identified as kaempferolpentose-glucuronic acid isomer [47]. The two peaks 24 and 26 with molecular ion peak at 651 and 635 and its fragments were found in accordance with two compounds tentatively identified as quercetin-acetyl disaccharides and kaempferolacetyl disaccharides $[54,55]$. These two compounds were 
TABLE 5: Quantity of compounds detected in $80 \%$ methanol extract, $n$-butanol, and aqueous fractions of fresh and dry Taif rose.

\begin{tabular}{|c|c|c|c|c|c|c|c|}
\hline \multirow{2}{*}{ Peak number } & \multirow{2}{*}{ Compound } & \multicolumn{3}{|c|}{ Fresh rose (mg/g extract) } & \multicolumn{3}{|c|}{ Dry rose (mg/g extract) } \\
\hline & & $80 \% \mathrm{MeOH}$ & $n-\mathrm{BuOH}$ & Aqueous & $80 \% \mathrm{MeOH}$ & $n-\mathrm{BuOH}$ & Aqueous \\
\hline 1 & Quinic acid ${ }^{\mathrm{a}}$ & 1546329 & 351441 & 1749393 & 2076361 & 731132 & 26452471 \\
\hline 2 & Gallic acid & 3.22 & 6.31 & - & 2.84 & 5.39 & - \\
\hline 3 & Digalloyl hexose $\mathrm{e}^{1}$ & 0.09 & 0.31 & - & 0.04 & 0.16 & - \\
\hline 4 & Methyl gallic acid derivative $^{2}$ & 3.57 & 7.6 & - & 2.1 & 5.3 & - \\
\hline 5 & Digalloyl HHDP hexose $^{1}$ & 1.03 & 2.84 & - & 1.17 & 2.80 & - \\
\hline 6 & Digalloyl deoxyhexose ${ }^{1}$ & 0.09 & 0.22 & - & 0.11 & 0.19 & - \\
\hline 7 & Digalloyl HHDP hexose $^{1}$ & 2.18 & 5.35 & - & 2.60 & 5.32 & - \\
\hline 8 & Unknown ellagitannin $^{1}$ & 1.57 & 4.06 & - & 1.12 & 2.66 & - \\
\hline 9 & Unknown ellagitannin ${ }^{1}$ & 2.52 & 6.30 & - & 1.72 & 3.85 & - \\
\hline 10 & Unknown ellagitannin $^{1}$ & 0.22 & 0.80 & - & 0.49 & 0.40 & - \\
\hline 11 & Unknown ellagitannin ${ }^{1}$ & 0.75 & 1.56 & - & 0.87 & 1.44 & - \\
\hline 12 & Quercetin-3-glucose-6-gallic acid & 1.33 & 1.38 & - & 0.64 & 1.43 & - \\
\hline 13 & Unknown ellagitannin $^{1}$ & 2.06 & 4.07 & - & 1.61 & 3.50 & - \\
\hline $14 a$ & Rutin & 0.10 & 0.17 & - & 0.10 & 0.24 & - \\
\hline $14 b$ & Quercetin 3-O- $\beta$-D-glucoside & 1.90 & 3.93 & - & 2.28 & 4.72 & - \\
\hline 15 & Quercetin-glucose-protocatechuic acid ${ }^{1}$ & 1.46 & 3.62 & - & 1.93 & 3.64 & - \\
\hline 16 & Quercetin-pentoside ${ }^{3}$ & 0.21 & 0.65 & - & 0.29 & 0.78 & - \\
\hline 17 & Kaempferol-hexose-gallic acid ${ }^{1}$ & 1.27 & 4.77 & - & 1.70 & 3.33 & - \\
\hline 18 & Quercetin/Kaempferol derivatives $^{4}$ & 2.81 & 5.88 & - & 3.43 & 6.66 & - \\
\hline 19 & Kaempferol 3-O- $\beta$-D-glucoside & 7.50 & 16.21 & - & 9.15 & 17.60 & - \\
\hline 20 & Kaempferol-hexose-gallic acid ${ }^{1}$ & 0.14 & 0.31 & - & 0.22 & 0.43 & - \\
\hline 21 & Kaempferol-pentoside ${ }^{5}$ & 0.53 & 1.30 & - & 0.87 & 1.50 & - \\
\hline 22 & Kaempferol-pentoside glucuronic acid ${ }^{4}$ & 1.95 & 5.21 & - & 2.65 & 5.71 & - \\
\hline 23 & Kaempferol 3-O- $\alpha$-rhamnoside & 0.54 & 1.31 & - & 0.88 & 1.50 & - \\
\hline 24 & Quercetin acetyl disaccharides ${ }^{4}$ & 0.23 & 0.50 & - & 0.21 & 0.58 & - \\
\hline 25 & Quercetin disaccharides ${ }^{4}$ & 0.26 & 0.65 & - & 0.19 & 0.66 & - \\
\hline 26 & Kaempferol acetyl disaccharides ${ }^{4}$ & 1.27 & 3.28 & - & 1.50 & 3.44 & - \\
\hline 27 & Kaempferol hexoside-deoxyhexose ${ }^{4}$ & 1.46 & 3.94 & - & 1.59 & 3.74 & - \\
\hline 28 & Unknown non-phenolic compound ${ }^{\mathrm{a}}$ & 2776578 & 6225284 & - & 541747 & 7069559 & \\
\hline
\end{tabular}

Quantified as ${ }^{1}$ quercetin-3-glucose-6-gallic acid; ${ }^{2}$ gallic acid; ${ }^{3}$ quercetin 3-O- $\beta$-D-glucoside; ${ }^{4}$ rutin, and ${ }^{5}$ kaempferol 3-O- $\alpha$-rhamnoside (including molecular weight correction factor).

${ }^{a}$ Due to lake of similar or related standard compounds, the quantity is represented by area under curve.

previously identified from the hydrodistilled petals from Rosa damascena [22]. The spectra of peaks 25 and 27 showed deprotonated molecular ion peaks $[\mathrm{M}-\mathrm{H}]^{-}$at $m / z 609$ and 593. The spectrum of peak 25 showed fragments 463, 447, and 301, whereas spectrum of peak 27 has fragments 447,430 , and 284. The two compounds were found to be characteristic of quercetin disaccharides and kaempferol disaccharides isomers, respectively, in which the two sugar moieties attached with the aglycon in two different situations $[22,43,46]$. The last peak 28 with molecular ion peak at 604 showed different fragments of phenolic compound, and then this unknown compound could be tentatively identified as non phenolic compound.

\section{Conclusions}

The results of this study provide evidence that the $80 \%$ methanol extracts, $n$-butanol, and remaining aqueous fractions for both fresh and dry Taif roses have high antioxidant and anticancer activities. The antioxidant properties were found to be associated with percentage of total phenolics in each extract, whereas no association between anticancer activity and total phenolics appeared. The phytochemical analysis for fresh and dry Taif roses using modern hyphenated technique including high performance liquid chromatography coupled by electrospray ionization mass spectrometry (HPLC-ESI-MS) indicates the presence of phenolic compounds belonging to hydrolysable tannins and flavonol glycosides of quercetin and kaempferol aglycones. From these results, the methanol extracts and its $n$-butanol and aqueous fractions for both fresh and dry Taif rose could be used as preventive and therapeutic effective natural agents for diseases in which free radicals are involved after more in vivo and in vitro studies.

\section{Conflict of Interests}

Authors have declared that there is no conflict of interests in this paper. 


\section{Acknowledgment}

The authors are very grateful to Taif University, Saudi Arabia, for supporting this work (Project no. 2-433-1871) and deeply grateful to the supporter of Chair of Research and Development Studied for Taif rose, Taif University, Saudi Arabia.

\section{References}

[1] E. S. Abdel-Hameed, S. A. Bazaid, M. M. Shohayeb, M. M. ElSayed, and E. A. El-Wakil, "Phytochemical studies and evaluation of antioxidant, anticancer and antimicrobial properties of Conocarpus erectus L. growing in Taif, Saudi Arabia," European Journal of Medicinal Plants, vol. 2, no. 2, pp. 93-112, 2012.

[2] M. J. Nirmala, A. Samundeeswari, and P. D. Sankar, "Natural plant resources in anti-cancer therapy-a review," Research Plant Biology, vol. 1, pp. 1-14, 2011.

[3] Y. Liu, B. Lu, L. Xu et al., "The antioxidant activity and hypolipidemic activity of the total flavonoids from the fruit of Rosa laevigata Michx," Natural Science, vol. 2, no. 3, pp. 175-183, 2010.

[4] E. Vamanu and S. Nita, "Antioxidant capacity and the correlation with major phenolic compounds, anthocyanin, and tocopherol content in various extracts from the wild edible Boletus edulis mushroom," Biomedical Research International, vol. 2013, Article ID 313905, 11 pages, 2013.

[5] S. Kazaz, S. Erbas, H. Baydar, T. Dilmacunal, and M. A. Koyuncu, "Cold storage of oil rose (Rosa damascena Mill.) flowers," Scientia Horticulturae, vol. 126, no. 2, pp. 284-290, 2010.

[6] Y.-Z. Cai, J. Xing, M. Sun, Z.-Q. Zhan, and H. Corke, "Phenolic antioxidants (hydrolyzable tannins, flavonols, and anthocyanins) identified by LC-ESI-MS and MALDI-QIT-TOF MS from Rosa chinensis flowers," Journal of Agricultural and Food Chemistry, vol. 53, no. 26, pp. 9940-9948, 2005.

[7] M. Jalali-Heravi, H. Parastar, and H. Sereshti, "Development of a method for analysis of Iranian damask rose oil: combination of gas chromatography-mass spectrometry with Chemometric techniques," Analytica Chimica Acta, vol. 623, no. 1, pp. 11-21, 2008.

[8] H. C. Baser, "Turkish rose oil," Perfume and Flavor, vol. 17, pp. 45-52, 1992.

[9] M. Kurkcuoglu and K. H. C. Baser, "Studies on Turkish rose concrete, absolute, and hydrosol," Chemistry of Natural Compounds, vol. 39, no. 5, pp. 457-464, 2003.

[10] E. Basim and H. Basim, "Antibacterial activity of Rosa damascena essential oil," Fitoterapia, vol. 74, no. 4, pp. 394-396, 2003.

[11] V. Singh, V. K. Kaul, B. Singh, and R. P. Sood, "Damask rose (Rosa damascena Mill.): cultivation and processing," in Supplement to Cultivation \& Utilization of Aromatic Plants, S. S. Handa and M. K. Kaul, Eds., p. 195, RRL Jammu Tawi, India, 1997.

[12] N. G. Baydar and H. Baydar, "Phenolic compounds, antiradical activity and antioxidant capacity of oil-bearing rose (Rosa damascena Mill.) extracts," Industrial Crops and Products, vol. 41, pp. 375-380, 2013.

[13] P. Skehan, R. Storeng, D. Scudiero et al., "New colorimetric cytotoxicity assay for anticancer-drug screening," Journal of the National Cancer Institute, vol. 82, no. 13, pp. 1107-1112, 1990.

[14] E. S. Abdel-Hameed, "Total phenolic contents and free radical scavenging activity of certain Egyptian Ficus species leaf samples," Food Chemistry, vol. 114, no. 4, pp. 1271-1277, 2009.
[15] E. S. Abdel-Hameed, S. A. Bazaid, and M. M. Shohayeb, "Total phenolics and antioxidant activity of defatted fresh Taif rose, Saudi Arabia," British Journal of Pharmaceutical Research, vol. 2, no. 3, pp. 129-140, 2012.

[16] N. Yassa, F. Masoomi, S. E. Rohani Rankouhi, and A. Hadjiakhoondi, "Chemical composition and antioxidant activity of the extract and essential oil of Rosa damascena from Iran, population of Guilan," DARU Journal of Pharmaceutical Sciences, vol. 17, no. 3, pp. 175-180, 2009.

[17] X. Li, W. Cao, Y. Shen et al., "Antioxidant compounds from Rosa laevigata fruits," Food Chemistry, vol. 130, no. 3, pp. 575-580, 2012.

[18] Y. Mikanagi, N. Saito, M. Yokoi, and F. Tatsuzawa, "Anthocyanins in flowers of genus Rosa, sections Cinnamomeae (= Rosa), Chinenses, Gallicanae and some modern garden roses," Biochemical Systematics and Ecology, vol. 28, no. 9, pp. 887-902, 2000.

[19] N. Kumar, P. Bhandari, B. Singh, A. P. Gupta, and V. K. Kaul, "Reversed phase-HPLC for rapid determination of polyphenols in flowers of rose species," Journal of Separation Science, vol. 31, no. 2, pp. 262-267, 2008.

[20] J. H. Lee, H.-J. Lee, and M.-G. Choung, "Anthocyanin compositions and biological activities from the red petals of Korean edible rose (Rosa hybrida cv. Noblered)," Food Chemistry, vol. 129, no. 2, pp. 272-278, 2011.

[21] N. Kumar, P. Bhandari, B. Singh, and S. S. Bari, "Antioxidant activity and ultra-performance LC-electrospray ionizationquadrupole time-of-flight mass spectrometry for phenolicsbased fingerprinting of Rose species: Rosa damascena, Rosa bourboniana and Rosa brunonii," Food and Chemical Toxicology, vol. 47, no. 2, pp. 361-367, 2009.

[22] A. Schieber, K. Mihalev, N. Berardini, P. Mollov, and R. Carle, "Flavonol glycosides from distilled petals of Rosa damascena Mill," Zeitschrift fur Naturforschung C, vol. 60, no. 5-6, pp. 379384, 2005.

[23] O. P. Tiwari and Y. B. Tripathi, "Antioxidant properties of different fractions of Vitex negundo Linn," Food Chemistry, vol. 100, no. 3, pp. 1170-1176, 2007.

[24] Y. F. Sasaki, S. Kawaguchi, A. Kamaya et al., "The comet assay with 8 mouse organs: results with 39 currently used food additives," Mutation Research, vol. 519, no. 1-2, pp. 103-119, 2002.

[25] M. H. Robya, M. A. Sarhan, K. A. Selim, and K. I. Khalel, "Evaluation of antioxidant activity, total phenols and phenolic compounds in thyme (Thymus vulgaris L.), sage (Salvia officinalis L.), and marjoram (Origanum majorana L.) extracts," Industrial Crops and Products, vol. 43, pp. 827-831, 2013.

[26] A. H. Goli, M. Barzegar, and M. A. Sahari, "Antioxidant activity and total phenolic compounds of pistachio (Pistachia vera) hull extracts," Food Chemistry, vol. 92, no. 3, pp. 521-525, 2005.

[27] K. Zhou and L. Yu, "Total phenolic contents and antioxidant properties of commonly consumed vegetables grown in Colorado," LWT-Food Science and Technology, vol. 39, no. 10, pp. 1155-1162, 2006.

[28] A. Wojdyło, J. Oszmiański, and R. Czemerys, "Antioxidant activity and phenolic compounds in 32 selected herbs," Food Chemistry, vol. 105, no. 3, pp. 940-949, 2007.

[29] A. D. Kinghorn, B.-N. Su, D. Lee, J.-Q. Gu, and J. M. Pezzuto, "Cancer chemopreventive agents discovered by activity-guided fractionation: an update," Current Organic Chemistry, vol. 7, no. 3, pp. 213-226, 2003. 
[30] D. Y.-K. But, C.-L. Lai, and M.-F. Yuen, "Natural history of hepatitis-related hepatocellular carcinoma," World Journal of Gastroenterology, vol. 14, no. 11, pp. 1652-1656, 2008.

[31] Z. Tian, G. Lin, R.-X. Zheng, F. Huang, M.-S. Yang, and P.G. Xiao, "Anti-hepatoma activity and mechanism of ursolic acid and its derivatives isolates from Aralia decaisneana," World Journal of Gastroenterology, vol. 12, no. 6, pp. 874-879, 2006.

[32] M. J. Balunas and A. D. Kinghorn, "Drug discovery from medicinal plants," Life Sciences, vol. 78, no. 5, pp. 431-441, 2005.

[33] N. H. Oberlies and D. J. Kroll, "Camptothecins and taxol: historic achievement in natural products research," Journal of Natural Products, vol. 67, no. 2, pp. 129-135, 2004.

[34] V. Vichai and K. Kirtikara, "Sulforhodamine B colorimetric assay for cytotoxicity screening," Nature Protocols, vol. 1, no. 3, pp. 1112-1116, 2006.

[35] J. Boik, Natural Compounds in Cancer Therapy, Oregon Medical Press, Princeton, Minn, USA, 2001.

[36] Z. Amir, R. Hasan, T. Zahra, and H. M. Seyed, "Study of cytotoxic properties of Rosa damascena extract in human cervix carcinoma cell line," Avicenna Journal of Phytomedicine, vol. 1, no. 2, pp. 74-77, 2011.

[37] W. Liu, S. Y. Li, X. E. Huang, J. J. Cui, T. Zhao, and H. Zhang, "Inhibition of tumor growth in vitro by a combination of extracts from Rosa roxburghii Tratt and Fagopyrum cymosum," Asian Pacific Journal of Cancer Prevention, vol. 13, pp. 24092414, 2012.

[38] T. B. Ng, J. S. He, S. M. Niu et al., "A gallic acid derivative and polysaccharides with antioxidative activity from rose (Rosa rugosa) flowers," Journal of Pharmacy and Pharmacology, vol. 56, no. 4, pp. 537-545, 2004.

[39] A. Kumaran and R. Joel Karunakaran, "In vitro antioxidant activities of methanol extracts of five Phyllanthus species from India," LWT-Food Science and Technology, vol. 40, no. 2, pp. 344-352, 2007.

[40] A. Romani, M. Campo, and P. Pinelli, "HPLC/DAD/ESI-MS analyses and anti-radical activity of hydrolyzable tannins from different vegetal species," Food Chemistry, vol. 130, no. 1, pp. 214221, 2012.

[41] D. H. M. Bastos, L. A. Saldanha, R. R. Catharino et al., "Phenolic antioxidants identified by ESI-MS from yerba maté (Ilex paraguariensis) and green tea (Camelia sinensis) extracts," Molecules, vol. 12, no. 3, pp. 423-432, 2007.

[42] M. Del Bubba, L. Checchini, U. Chiuminatto, S. Doumett, D. Fibbi, and E. Giordani, "Liquid chromatographic/electrospray ionization tandem mass spectrometric study of polyphenolic composition of four cultivars of Fragaria vesca L. berries and their comparative evaluation," Journal of Mass Spectrometry, vol. 47, pp. 1207-1220, 2012.

[43] C. Engels, D. Gräter, P. Esquivel, V. M. Jiménez, M. G. Gänzle, and A. Schieber, "Characterization of phenolic compounds in jocote (Spondias purpurea L.) peels by ultra high-performance liquid chromatography/electrospray ionization mass spectrometry," Food Research International, vol. 46, no. 2, pp. 557-562, 2012.

[44] L. Barrosa, C. T. Alves, D. Dueñas et al., "Characterization of phenolic compounds in wild medicinal flowers from Portugal by HPLC-DAD-ESI/MS and evaluation of antifungal properties," Industrial Crops and Products, vol. 44, pp. 104-110, 2013.

[45] J. Dou, V. S. Y. Lee, J. T. C. Tzen, and M.-R. Lee, "Identification and comparison of phenolic compounds in the preparation of oolong tea manufactured by semifermentation and drying processes," Journal of Agricultural and Food Chemistry, vol. 55, no. 18, pp. 7462-7468, 2007.

[46] B. Abad-García, L. A. Berrueta, S. Garmón-Lobato, B. Gallo, and F. Vicente, "A general analytical strategy for the characterization of phenolic compounds in fruit juices by highperformance liquid chromatography with diode array detection coupled to electrospray ionization and triple quadrupole mass spectrometry," Journal of Chromatography A, vol. 1216, no. 28, pp. 5398-5415, 2009.

[47] K. Hanhineva, I. Rogachev, H. Kokko et al., "Non-targeted analysis of spatial metabolite composition in strawberry (Fragaria ananassa) flowers," Phytochemistry, vol. 69, no. 13, pp. 24632481, 2008.

[48] Y. Sudjaroen, W. E. Hull, G. Erben et al., "Isolation and characterization of ellagitannins as the major polyphenolic components of Longan (Dimocarpus longan Lour) seeds," Phytochemistry, vol. 77, pp. 226-237, 2012.

[49] B. Pfundstein, S. K. El Desouky, W. E. Hull, R. Haubner, G. Erben, and R. W. Owen, "Polyphenolic compounds in the fruits of Egyptian medicinal plants (Terminalia bellerica, Terminalia chebula and Terminalia horrida): characterization, quantitation and determination of antioxidant capacities," Phytochemistry, vol. 71, no. 10, pp. 1132-1148, 2010.

[50] P. Riehle, M. Vollmer, and S. Rohn, "Phenolic compounds in Cistus incanus herbal infusions-antioxidant capacity and thermal stability during the brewing process," Food Research International, vol. 53, no. 2, pp. 891-899, 2013.

[51] M. B. Arnao, A. Cano, J. F. Alcolea, and M. Acosta, "Identification of hydrolysable tannins in the reaction zone of Eucalyptus nitens wood by high performance liquid chromatographyelectrospray ionisation mass spectrometry," Phytochemical Analysis, vol. 12, no. 2, pp. 120-127, 2001.

[52] U. A. Fischer, R. Carle, and D. R. Kammerer, "Identification and quantification of phenolic compounds from pomegranate (Punica granatum L.) peel, mesocarp, aril and differently produced juices by HPLC-DAD-ESI/MSn," Food Chemistry, vol. 127, no. 2, pp. 807-821, 2011.

[53] E. Hvattum and D. Ekeberg, "Study of the collision-induced radical cleavage of flavonoid glycosides using negative electrospray ionization tandem quadrupole mass spectrometry," Journal of Mass Spectrometry, vol. 38, no. 1, pp. 43-49, 2003.

[54] G. Fico, A. Braca, A. R. Bilia, F. Tomè, and I. Morelli, "Flavonol glycosides from the flowers of Aconitum paniculatum," Journal of Natural Products, vol. 63, no. 11, pp. 1563-1565, 2000.

[55] L. Y. Foo, Y. Lu, A. L. Molan, D. R. Woodfield, and W. C. McNabb, "The phenols and prodelphinidins of white clover flowers," Phytochemistry, vol. 54, no. 5, pp. 539-548, 2000. 

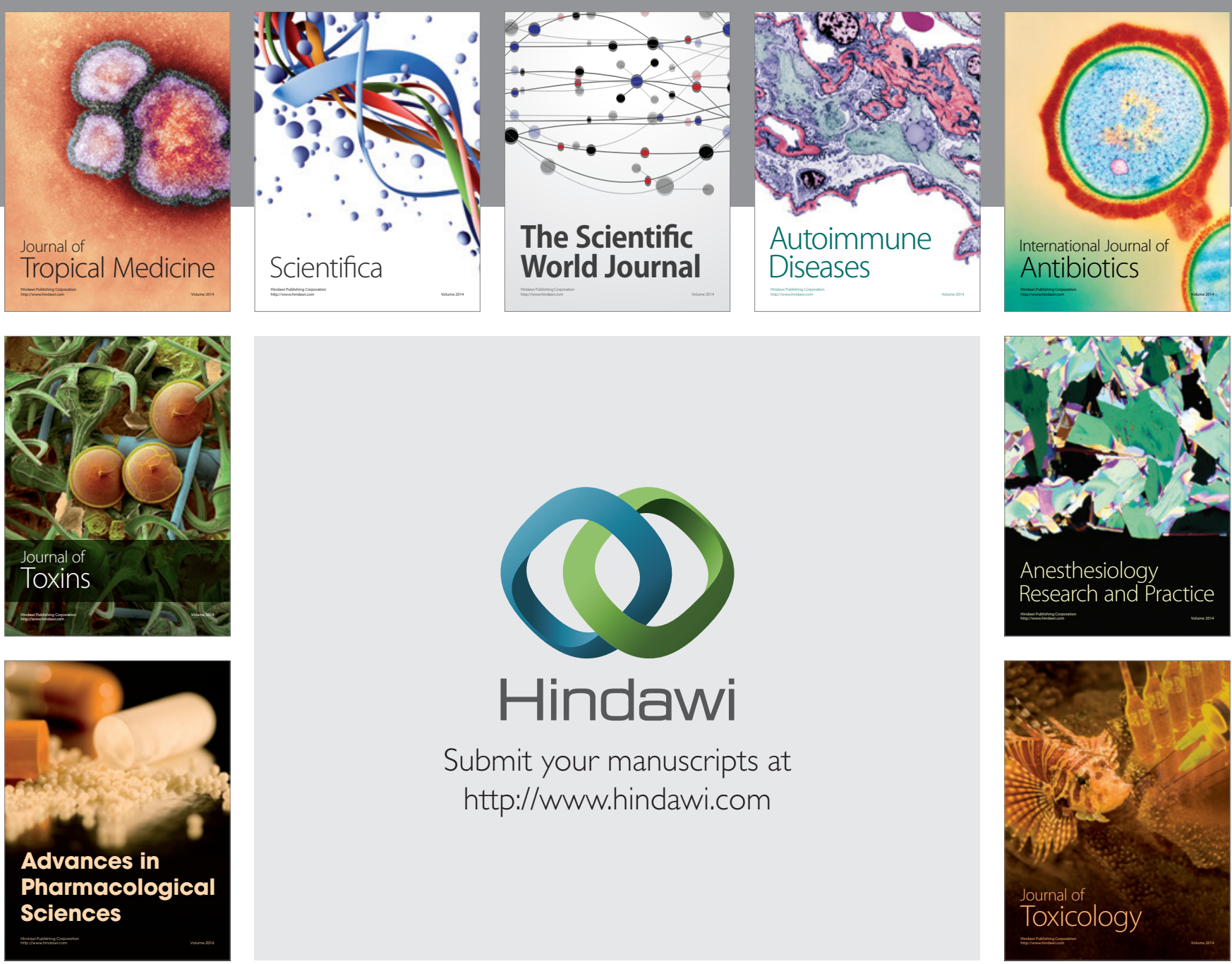

\section{Hindawi}

Submit your manuscripts at

http://www.hindawi.com
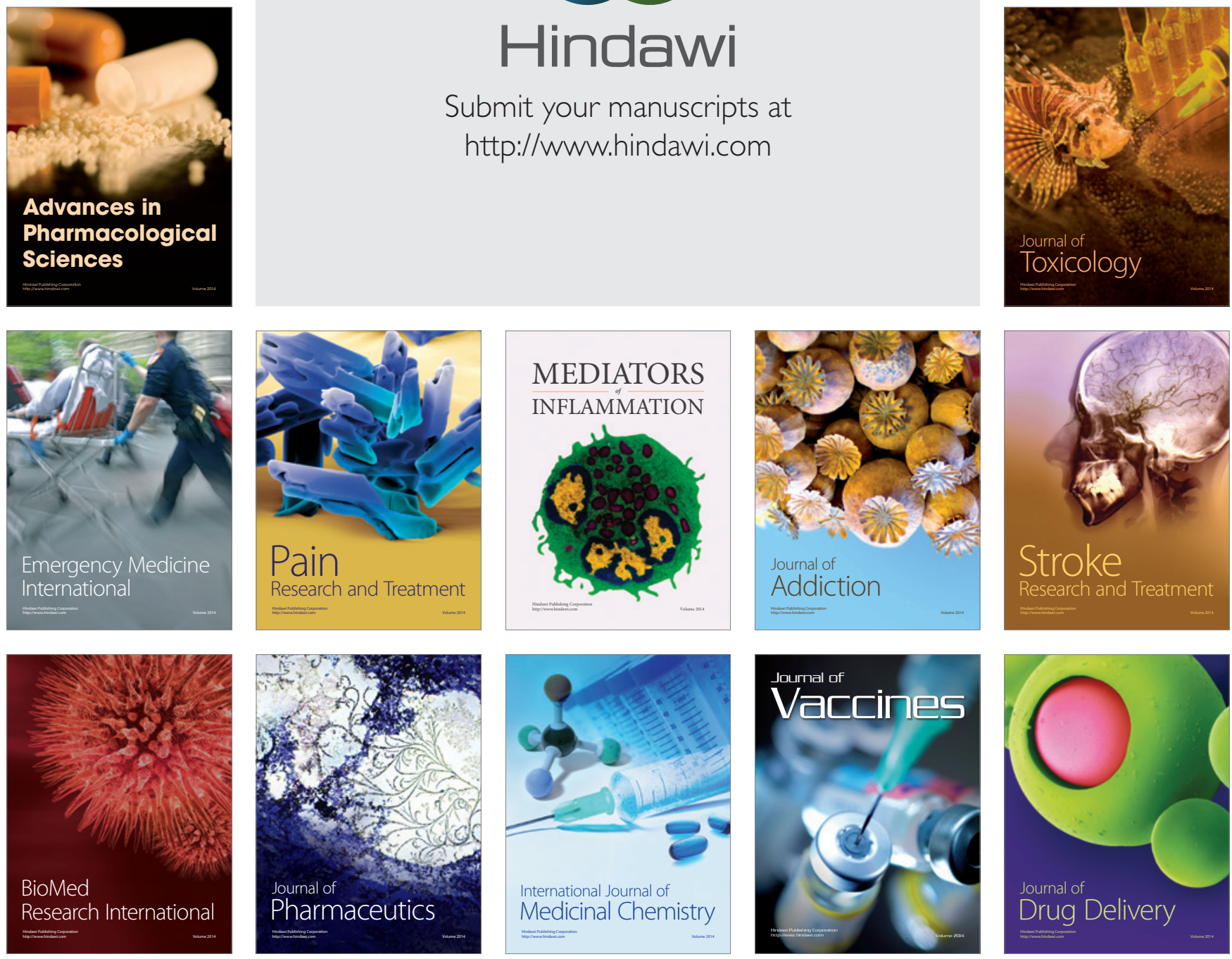